\title{
Optimal Sizing and Positioning of Grid Integrated Distributed Generator using Particle Swarm Optimization
}

\author{
Arpita De
}

\begin{abstract}
The intermittent nature of non-conventional energy sources is a major concern in Designing and Simulation of the Integration of a Distributed Generator (DG) in an existing system. Expansive sizing of any system increases the cost of the system and under sizing causes a lack of reliability and poor voltage regulation. In this paper optimal DG - Solar PV System positioning and sizing method has been proposed using particle swarm optimization algorithm (PSO). Optimal positioning and sizing of the system has been calculated for a photovoltaic system considering annualized cost of the system and reliability constraint. The DG system is simulated to determine the position and size of the system component to test the effectiveness of the proposed algorithm over the energy based system sizing method. Simulation and test results prove that the proposed optimal system configuration is able to supply the load annually with the optimum system installation cost along with its payback period.

Keywords: Renewable Energy, Distributed Generator, Solar PV, Grid Integration, Positioning, Sizing, Particle Swarm Optimization
\end{abstract}

\section{INTRODUCTION}

The quick industrialization in the course of recent decades because of globalization, creations in new advances and sustainable energy sources, for example, wind, sun, water, ocean and biomass, have become better options for traditional energy sources. Distributed Generator Energy System (DGES) is made out of one inexhaustible and one customary energy source, that works in independent or grid network associated mode [1]. DGES is getting prevalent for remain solitary power age in disconnected destinations because of the advances in sustainable power source innovations.

The significant component of DGES is to join inexhaustible power generation innovation to utilize their working capabilities and to get efficiencies higher than that could be gotten from a solitary power source. DGES can address confinements as far as adaptability, productivity, dependability, outflows and financial aspects.

DGES guarantees continuous and successful supply of capacity to the consumer load end. Solar Photovoltaic (PV) is sustainable, support on-site generation capability and is non-polluting. In any case, independent PV array can fulfill the load demand for the time during which daylight is accessible. This paper is centered on PV based DGES

Revised Manuscript Received on December 30, 2019.

* Correspondence Author

Arpita De*, Energy Centre, Maulana Azad National Institute of Technology (MANIT), Bhopal, India. Email: arpita.1802@gmail.com

(C) The Authors. Published by Blue Eyes Intelligence Engineering and Sciences Publication (BEIESP). This is an open access article under the CC BY-NC-ND license (http://creativecommons.org/licenses/by-nc-nd/4.0/)
Because of space and climate confinements. The measure of intensity created by a PV cluster relies upon the working voltage of the exhibit and the Maximum Power Point (MPP), which change with solar irradiation and temperature. MPP indicates a novel working point on PV trademark at which most extreme conceivable power can be extracted [2]. The yield intensity of the solar oriented module is profoundly influenced by the solar incident edge and its proficiency can be improved if the sunlight based module inclination is appropriately introduced at the ideal point. Huge research on financial and natural parts of incorporating the PV framework with lattice has been accounted for [3]

The paper talks about principle areas for the unit sizing and location of the DGES, displaying of the significant parts utilized in PV module alignment with customary lattice framework. The optimized capacity and desired location advancement study is basic before setting up or establishment of a DGES. These structure targets are normally clashing with each other and consequently a sensible exchange off between them is attractive.

Enhanced sizing of the arrangement of components will increase the system cost whereas lowering the sizing of the system can lead to failure of energy generation system. So, utmost care should be taken to design an optimized system at the best costing.

Particle Swarm Optimization (PSO) is an enhancement calculation viewed as exceptionally efficient for the arrangement of entangled problems. This paper displays the use of this technique to plan advancement of photovoltaic DGES. The motivation behind the proposed procedure is to find the ideal area and the ideal size of the PV module establishment in detail, to such an extent that the absolute net monetary benefit accomplished during the framework operational lifetime period is amplified [4]. The streamlining's choice factors are the ideal number of the PV modules, the ideal situation of the PV modules inside the accessible establishment zone and the ideal dissemination of the PV modules among the DC/AC converters.

The target function of the proposed advancement process is the lifetime framework's absolute net profit which is determined by the strategy for the Net Present Value (NPV). The approach's subsequent framework structures are monetarily assessed through the strategies for the limited restitution time and the Internal Rate of Return (IRR). 


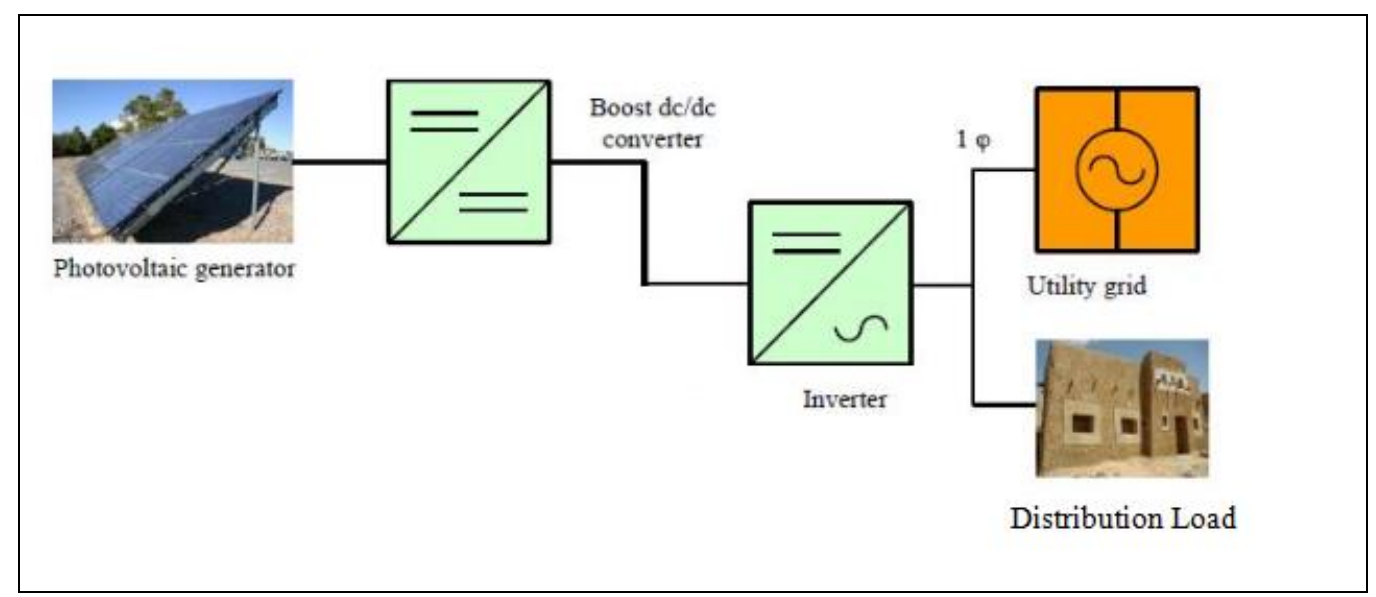

Figure 1: Schematic for the general system

Figure 1 shows the general schematic of the system in which PV module generates energy and transfers energy to the load and the utility grid. A graphical representation shows the groups of the different measuring techniques are represented in Fig. 2. This expansive characterization depends on the accessibility and non-accessibility of climate information, for example, insolation, clearness index and so on [5]. At the point when climate information is accessible, ordinary measuring approaches are utilized and are grouped based on idea of vitality equalization and unwavering quality of supply. Nonetheless, ordinary methods need long haul meteorological information for measuring of PV frameworks, which may not be accessible in remote disengaged destinations. In this manner, non-accessibility of climate information in remote locales has asked the scientists to investigate Artificial Intelligence (AI) systems, for example, Artificial Neural Networks (ANN), Fuzzy Logic
(FL), Genetic Algorithms (GA) or a half breed of such procedures [6].

Ordinary estimating techniques are being used for over two decades and give exact outcomes when real climate information is accessible. One of the straightforward methods for estimating segments depends on the idea of energy balance. The daily normal accessible energy from the sun and the load requests are adjusted to decide the quantity of PV modules required. The accessible energy from the sun can be resolved from sunlight based insolation information. Estimating dependent on energy balance contemplates the way misfortunes and efficiencies of the source, converters and controllers. Paper [7] proposes a calculation to decide the insignificant framework arrangement utilizing an iterative method dependent on energy balance. The ideal size of the framework segments depends on PV module framework, generating onsite power for ideal voltage regulation system.

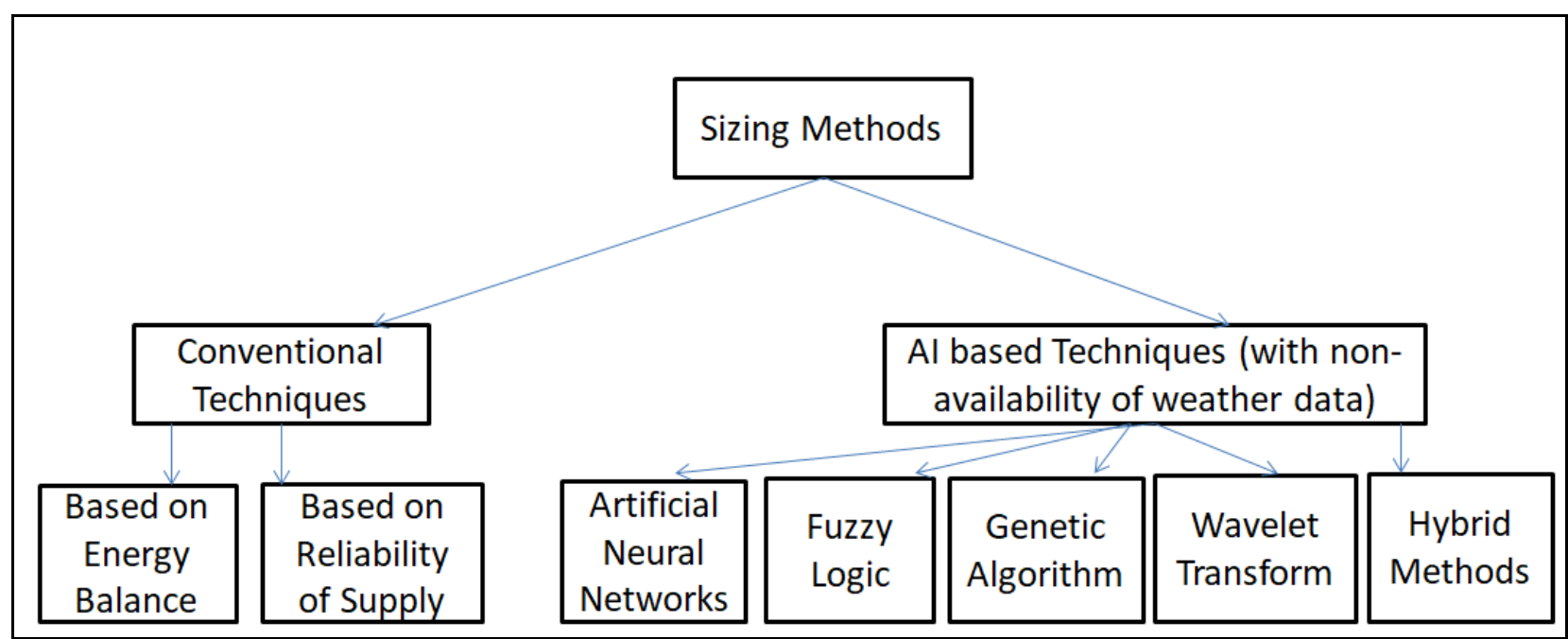

Figure 2: Bifurcation of DGES system Location and Sizing methods

\section{SYSTEM DESCRIPTION}

The DGES are recognized as a viable option for grid supply for remote area applications all over the world. In-depth operational and economic analysis of renewable energy based DGES, requires simulation of the system Numbers of software platform like MATLAB, LabView and tools like ETAP are available in which individual components are selected and integrated as RES for dynamic analysis. ETAP does the simulation to obtain an optimal configuration of
RES. It is most commonly used because of its simplicity, user friendly nature and satisfactory results. For designing and developing the Renewable Energy System (RES) for the identified site, prerequisite are meteorological data and load estimation. Load estimation of above location is performed, which is realized out of the daily consumption of electricity as per the population and ensuring minimum possible electrification in the present scenario.

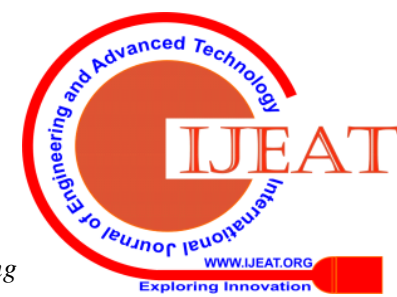




\section{Site Details}

Figure 3 depicts the details about the region - Jhalawar, for the study of distribution losses a test area Piplod Grid Sub-Station in the Jhalawar Circle, Rajasthan State, India. It has been considered for study, which consist of four feeders a- Bali feeder, Kishanpuriya feeder, Piplod village feeder and Deetyakhedi feeder.

\begin{tabular}{|c|c|c|c|}
\hline \multicolumn{2}{|c|}{ 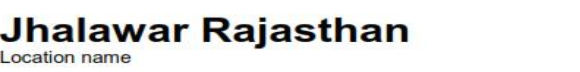 } & $\begin{array}{l}24.378 \\
\text { Latitude ['N] } \\
363 \\
\text { Altitude [m a.s.l.] }\end{array}$ & $\begin{array}{l}76.364 \\
\text { Longitude }\left[^{\circ} \mathrm{E}\right] \\
\mathrm{V}, 4 \\
\text { Climate region }\end{array}$ \\
\hline $\begin{array}{l}\text { Standard } \\
\text { Radiation model }\end{array}$ & $\begin{array}{l}\text { Standard } \\
\text { Temperature model }\end{array}$ & $\begin{array}{l}\text { Perez } \\
\text { Tilt radiation model }\end{array}$ & \\
\hline $\begin{array}{l}\text { 2000-2009 } \\
\text { Temperature period }\end{array}$ & $\begin{array}{l}\text { 1991-2010 } \\
\text { Radiation period }\end{array}$ & & \\
\hline \multicolumn{4}{|c|}{ Additional information } \\
\hline \multicolumn{4}{|c|}{$\begin{array}{l}\text { Uncertainty of yearly values: } \mathrm{Gh}=7 \%, \mathrm{Bn}=13 \%, \mathrm{Ta}=1.5{ }^{\circ} \mathrm{C} \\
\text { Trend of } \mathrm{Gh} / \mathrm{f} \text { decade: } \\
\text { Variability of } \mathrm{Gh} / \text { yearar: } 5.4 \%\end{array}$} \\
\hline
\end{tabular}

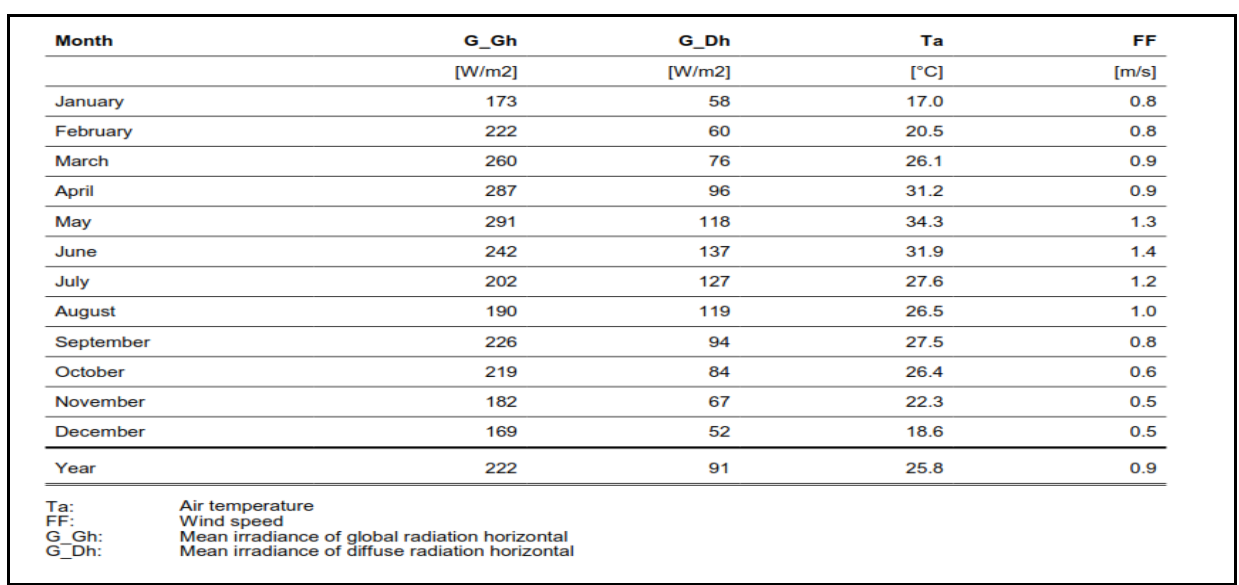

Figure 3: Data of Jhalawar District, Rajasthan

The below figures 4, shows the Monthly radiation, Daily global radiation, Monthly temperature and Sunshine hours in Jhalawar District, Rajasthan.

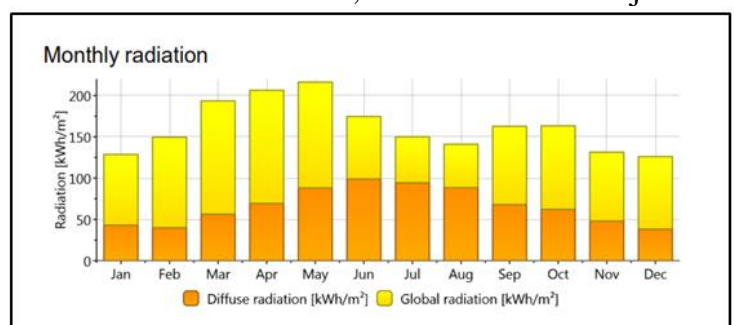

(a)

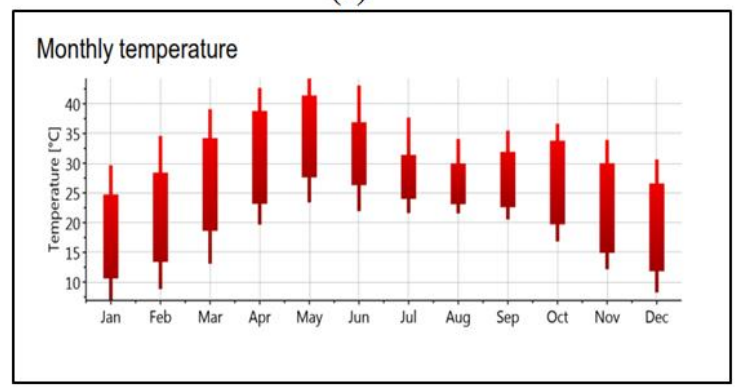

(c)

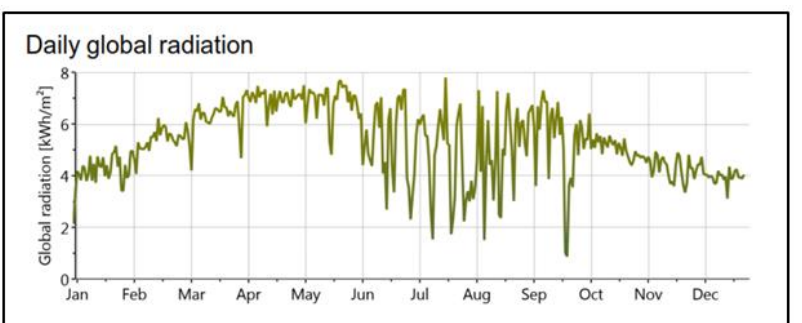

(b)

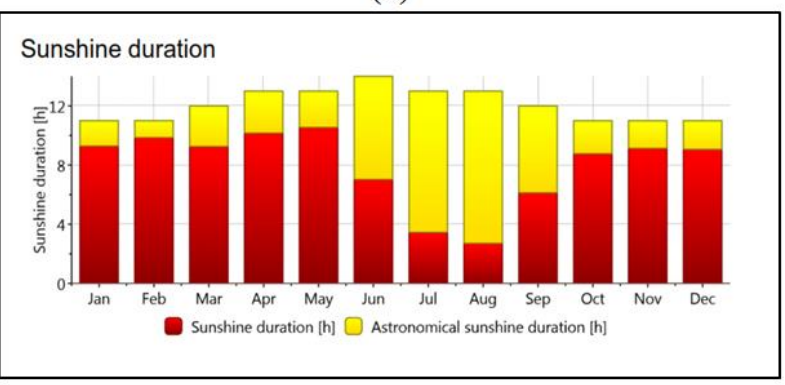

(d)

Figure 4: (a) Monthly solar irradiance (b) Daily global solar irradiance (c) Monthly Average Temperature (d) Sunshine radiation 
Figure 5 shows the Deetyakhedi feeder, Piplod Grid Sub-Station in the Jhalawar Circle, Rajasthan State. The study deals with the equivalent one line diagram network software representation based on the electrical single line diagram. This report considers the computer based Power System Study to analyze the generation time and control dispersion framework as pertinent to the feeder power plant.

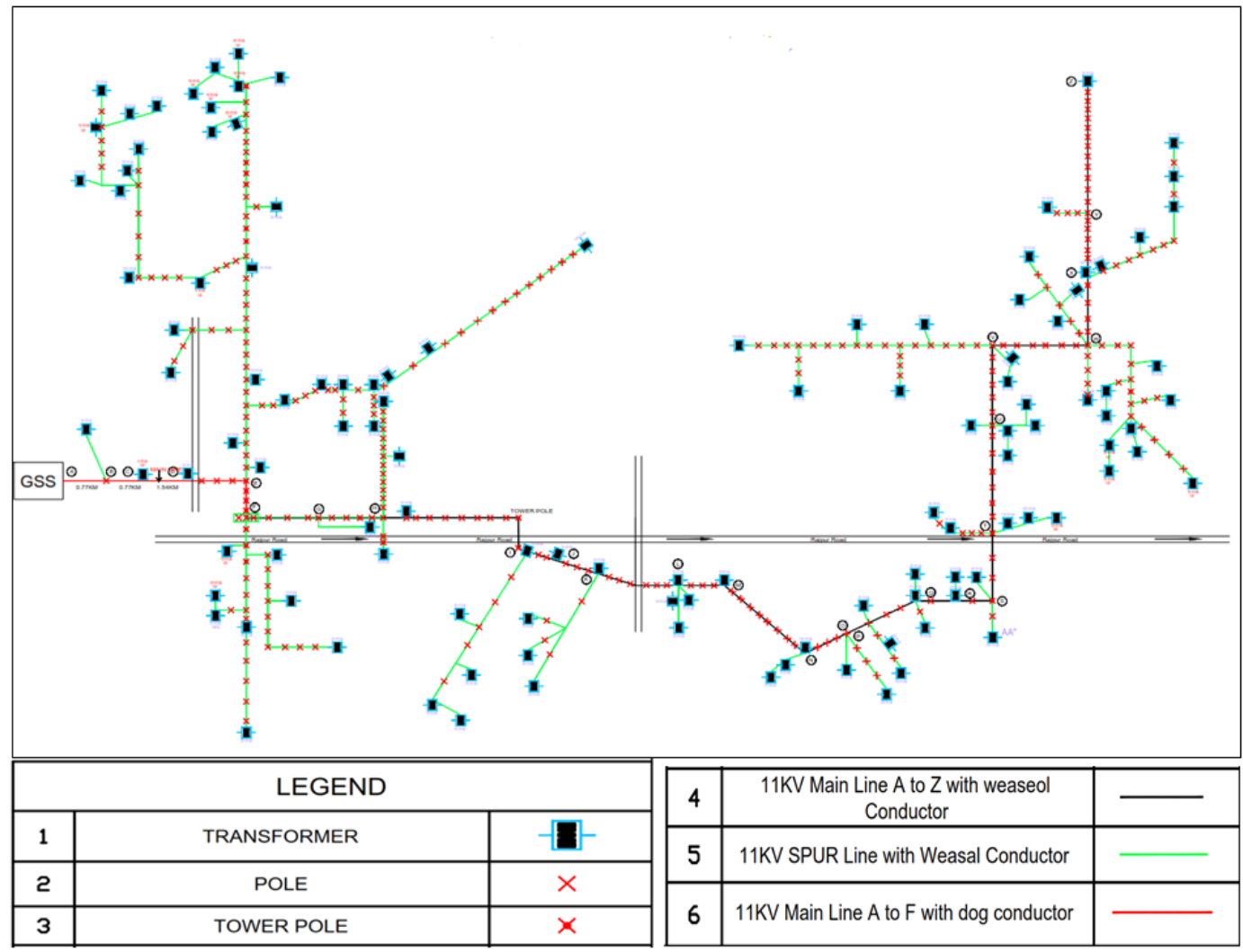

Figure 5: Single Line diagram of Deetyakhedi feeder

applied. The measure of the research work is the boost of the

Load Flow study has been carried out based on the IEEE Standard 399-1997, of ETAP Power Station software (Version 12.6) and Adaptive Newton-Raphson method has been used to perform the load flow study.

\section{THE PROPOSED METHODOLOGY}

The calculation's has been done from database containing the specialized and monetary attributes of financially accessible devices alongside meteorological information for the selection for the establishment site with reference to Voltage Profile and losses. The financial characteristics of the system's components are the installation cost and the yearly maintenance charges. Load Flow Analysis is done on the proposed system - Deetyakhedi feeder to find out the nodes with the maximum voltage drop.

After studying various Renewable Energy Distributed Generator Sources viability around the Feeder system, a combination of PV array is chosen and its characteristics are taken from the predefined database. The remainder of parameters stacked from the database are the hourly sun oriented illumination and encompassing temperature values during the year, the accessible region measurements, the nearby economy's parameters and finally, parameters utilized for the calculation of the expense of the land and the mounting structures of PV modules.

The next step is finding Optimal Size of the system at the appropriate Location for the Solar PV DG System. This step comprises of the PSO parameters, as well as appropriate algorithms for solving the problem's limiting factors and analyzing the available parameters. On the off chance that an answer isn't plausible, an appropriate fixing calculation is
DGES parameters for the decrease of Voltage Regulation, decrease of reliability misfortunes and the expansion of the net profits accomplished during the framework operational period. The general ideal DGES structure are shown and put away alongside the determined monetary suitability pointers which are the limited compensation time and the Internal Rate of Return (IRR). The descriptive flow of the proposed technique's calculation is showed in Fig. 6.

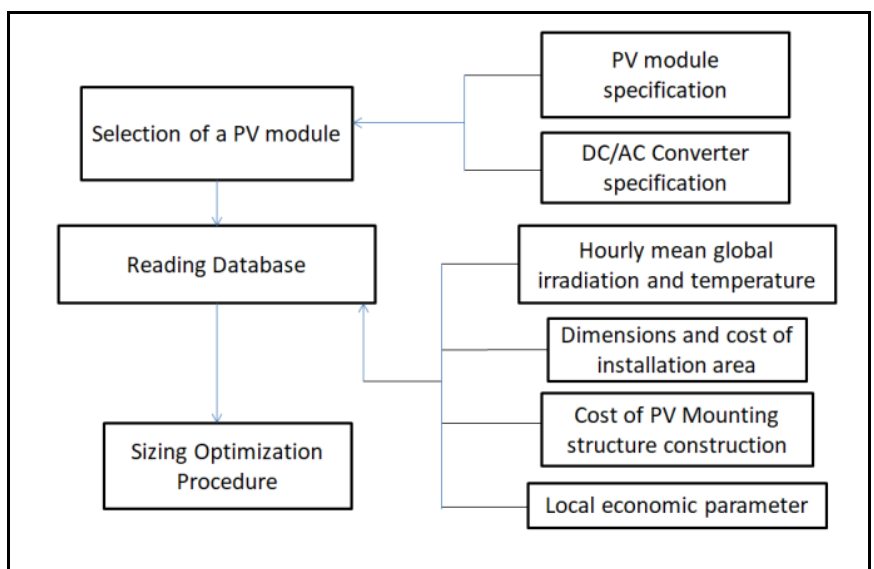

Figure 6: Descriptive Flow of the proposed work

Published By:

Blue Eyes Intelligence Engineering \& Sciences Publication 


\section{PROBLEM FORMULATION}

In India, renewable energy has come out as an important sector in the energy generation. It has been understood that sustainable power source needs to assume an a lot further role in accomplishing energy security in the years ahead and be a vital piece of the energy allocating process [8].

Comprehensive literature study is done for the various design phases of Renewable Energy System (RES) is carried out at site which will deliver power in efficient and economical manner. A detailed literature review is divided in three categories - i) Integration of Distributed generator (DG) as RES, ii) Modelling and simulation of DG, iii) Optimization

\section{(i) Integration of Distributed Generator}

Solar Photovoltaic (PV), wind, hydro, fuel cells, biogas, etc. are typical sources of small-scale generation as distributed generator [9]. Renewable based distributed generator has pulled in the consideration of intensity framework originators as a dependable answer for breakdown of the constraints that exist toward development of electric power network, low petroleum derivative stores and ecological concern [10]. Especially for rural and remote areas distributed generator offers wider user choices and causes lower emission [11]. Distributed generator capacity ranges between $\mathrm{kW}$ to MW depending on the space availability [12]. The essential wellspring of energy for these generators can be the inexhaustible sources, for example, wind, Solar, hydro, and biomass [13]. These generators are associated either to the medium voltage or low voltage segments of the electric framework on the Distribution side [14]. Regularly DG's are associated close to the heap focuses or the low voltage systems [15]. If generation of electrical energy is near to consumer's point, then it will become an important parameter for the demand satisfaction with a reduced economic and environment prices [16]. Several projects have been observed to supply power from various grid-connected renewable based distribution generations such as solar, wind, hydro etc. The economic viability of these projects has been analyzed as compared to electricity generation through various non-renewable energy sources for the isolated communities [17].

\section{(ii)Modelling and Simulation of DG}

For real time analysis of DGES, the system model is to be developed. Every individual component of the system is modelled in available simulation platform like MATLAB, ETAP (Electrical Transient and Analysis Program), LabVIEW, PVSyst etc. In these tools generally components are already available in their library function or can be modelled by their mathematical equations to represent their real time behavior. [18]

In literature various types of modelling of components is studied and then the system is simulated to analyse the performance of RES for its variations in load profile, environmental conditions and any other unforeseen circumstances [19]. A unique model and recreation of different sunlight based cell/wind turbine/energy component crossover control frameworks are considered utilizing different topologies to supplement one another and to reduce the impacts of ecological varieties [20]. Modelling and simulations can be led utilizing different programming bundles to check the adequacy of a proposed framework [21]. The approach is embraced to show that the proposed framework is fit for enduring the fast change in the load profile [22].To oversee control stream among different energy sources and capacity unit to fulfil load request, a general power generation methodology is recommended for the framework. Under various situations, the framework execution investigation is considered utilizing a practical performance is studied with practical climate data information [23].

\section{(iii) Optimization of DG}

The techno-monetary investigation of the framework is fundamental for the productive use of sustainable power source assets [24]. Because of different age frameworks, vitality framework examination, is very intricate and requires to be broke down altogether. This requires programming instruments and enhancement methods for the operational and financial investigation of the frameworks. [25]. As calculation intensity of current PCs is expanding significantly, PC based re-enactments and improvement have gotten increasingly more consideration, and are turning into a significant apparatus for the structure of intensity models [26]. Various types of software tools are available for real time system integration of HES to analyse for different stages of its designing like prefeasibility analysis tools (e.g. RETSCREEN)[27], simulation tools (e.g. PVSYST and PV Design Pro mainly for solar PV) and open architecture simulation tools (e.g. MATLAB and Simulink)[28]. In already developed software tools, power dispatch strategy and energy flows among sources are already decided so user does not have to do a large number of modifications in system parameters [29]. Need of the hour is to develop a user friendly algorithm to have economic design of DGES at any location. So as to get power from inexhaustible DGES dependably and at monetary value, its structure must be ideal as far as activity and part determination [30]. The ideal measuring of such frameworks requires itemized examination for a given area because of impact of different site subordinate factors, for example, solar powered radiation, wind speed, temperature and their connection to grid framework cost [31].

\section{MODELLING OF SOLAR PHOTOVOLTAIC (PV) SYSTEM}

A solar based photovoltaic (PV) framework changes over the sun energy into power. The smallest unit of this framework is the solar cell. Cells are then masterminded in the module which is additionally associated in arrangement as well as parallel design to frame clusters. The DC power created at the terminals of the clusters can be utilized in an assortment of uses, for example, in engines, lighting modules and so on. The PV framework is exceptionally non-straight as can be clear from its present v/s voltage (I-V) qualities appeared in Fig. 7. It shows either current source or voltage source conduct contingent upon the working point lying on the left or right of P, separately. At Maximum Power Point (MPP), result of voltage (Vmp) and current (Imp) is most extreme. Isc and Voc are open circuit voltage and short circuit current, separately. 


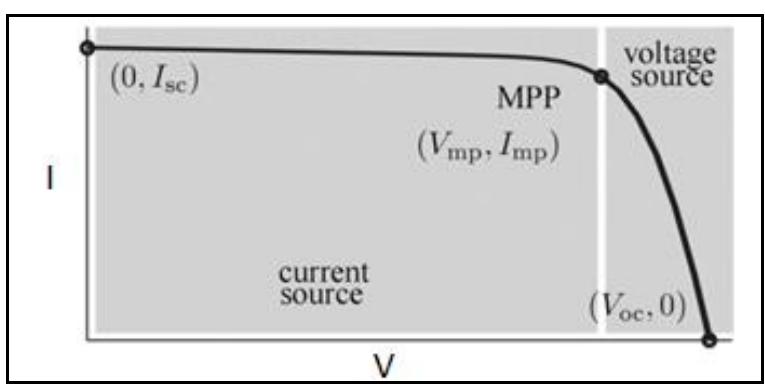

Figure 7: V-I characteristics of PV module Objective function and Constraints formulation for Solar PV:

There are many aspects that are considered to do the sizing of grid connected Distributed generator system. Among the main reasons, the parameter that must be minimized is the Voltage regulation and the cost function.

a) Cost Parameters:

In this investigation, capital expense of establishment all things considered, substitution cost, activity and support cost has been considered while computing Annual System Cost (ASC) of the framework over the entire task lifetime of 25 years. ASC can be determined as pursues:

ASC $=\mathbf{C}_{\text {cap }}(\mathbf{j})+\mathbf{C}_{\text {rep }}(\mathbf{j})+\mathbf{C}_{\text {om }}(\mathbf{j})$

Where, $C_{\text {cap }}(j)$ is Initial capital cost of system, $C_{\text {rep }}(j)$ is replacement cost of system and $\mathrm{C}_{\mathrm{om}}(\mathrm{j})$ is op. and maint. Cost of system.

\section{b) System Constraints:}

(i) Voltage Regulation (VR) Minimization

$\mathbf{V R}=\left(\mathbf{V}_{\mathbf{N L}}-\mathbf{V}_{\mathbf{L}}\right) / \mathbf{V}_{\mathbf{L}}$

At any given instant of time,

$\mathbf{V}_{\mathbf{L}}=\mathbf{I}_{\mathbf{L}} \mathbf{R}_{\mathbf{L}}$

$\mathbf{I}_{\mathbf{L}}=\mathbf{I}_{\text {grid }}+\mathbf{I}_{\text {solar }}$

So, the value of $I_{\text {solar }}$ is regulated to determine the size of Solar in such a way that the Voltage Regulation is minimized.

\section{(ii)Solar Array Sizing}

The number of solar modules is calculated using minimum and maximum permissible Voltage regulation range.

PV array minimum sizing is decided by the Output power at minimum Voltage Regulation and maximum PV panel efficiency.

$\mathrm{N}_{\text {PVmin }} \leq \mathrm{N}_{\mathrm{PV}} \leq \mathrm{N}_{\mathrm{PVmax}}$

$\mathrm{N}_{\mathrm{PV} \min } \geq \mathrm{P}_{\mathrm{Lmin}} /\left(\Pi_{\mathrm{PV}} * \mathrm{P}_{\mathrm{RPV}}\right)$

Where,

$\mathrm{P}_{\text {Lmin }}=$ Load at Min Voltage Regulation

$\eta_{\mathrm{PV}}=$ Overall efficiency for solar PV modules

$\mathrm{N}_{\text {PVmin }}=$ Minimum number of solar PV modules

$\mathrm{N}_{\text {PVmax }}=$ Maximum number of solar PV modules

$\mathrm{P}_{\mathrm{RPV}}=$ Rated Power of one Solar PV panel

Considering the variability in the resultant power of solar PV, maximum numbers of solar

PV panel is decided by the maximum value of permissible voltage regulation.

$\mathrm{N}_{\mathrm{PV} \max } \leq \mathrm{P}_{\text {Lmax }} /\left(\Pi_{\mathrm{PV}} * \mathrm{P}_{\mathrm{RPV}}\right)$

Where

$\mathrm{P}_{\text {Lmax }}=$ Load at Max Voltage regulation

Optimization of System with Particle Swarm

Optimization (PSO):

The optimal positioning and sizing of solar PV as DG is essential to optimize the net present cost of the energy system. The cost function takes into account the capital cost of installation, operation and maintenance cost for each component of the system and penalty cost for not delivering power to load after a certain limit [32]. The sizing problem has been formulated as a non-linear, multi-variable problem and Particle Swarm Optimization (PSO) technique on MATLAB platform has been used to find the optimum solution. In this segment PSO technique, adopted power management strategy, problem formulation and developed algorithm along with validation has been presented.

\section{PSO Optimization Algorithm}

The PSO is a multi-operator parallel inquiry advancement procedure; a developmental strategy which is propelled by the social conduct of birds, fish tutoring and swarm hypothesis [33]. The PSO thought depends on forcing different particles for looking through the ideal arrangement. Every molecule in the PSO calculation speaks to a potential arrangement; these arrangements are surveyed by the enhancement target capacity to decide their wellness.

The PSO plan depends on forcing different particles for looking through the ideal arrangement. Every molecule in the PSO calculation speaks to a potential arrangement; these arrangements are surveyed by the improvement target capacity to decide their wellness. In the following emphasis, the arrangements number duplicates until it gets the ideal one. Forcing more particles in every cycle urge going to the ideal arrangement, besides diminishes the quantity of enhancement emphases. So as to move to the ideal arrangement, particles move around in a multidimensional hunt space. The best understanding for every molecule is put away in the molecule memory (pbest) and the best worldwide acquired among all particles is called as a global best molecule (gbest). During flight the present position $\left(x_{i}\right)$ and speed $\left(v_{i}\right)$ of every molecule $(i)$ is adjusted by its very own understanding and the experience of neighbouring particles as portrayed by the accompanying conditions:

$v_{i}^{(g+1)}=\omega v_{i}^{g}+c_{1} a_{1}\left(\right.$ pbest $\left.-x_{i}^{(g)}\right)+c_{1} a_{2}\left(\right.$ gbest $\left.-x_{i}^{(g)}\right)$

$x_{i}{ }^{(g+1)}=x_{i}^{(g)}+v_{i}^{(g+1)}$

Where, $g$ is the number of generations, and $\omega$ is the inertia factor in a range of $[0.5,1] c_{1}$ and $c_{2}$ are positive acceleration constants, recognized as self-confidence factor and swarm confidence factor, respectively, $a_{1}$ and $a_{2}$ are uniform randomly generated numbers in a range of $[0,1]$ [34]. Swarm group sizing, number of particles, $\omega, c_{1}$ and $c_{2}$ are the main parameters of the PSO algorithm, which are initialized, based on the problem of the size and positioning being considered for optimization. The Figures 8 describes the flowchart with various steps of proposed methodology for the validation of the PSO Optimization technique and calculates the optimum sizing and positioning parameters of the DG system. In this flowchart, in the first step we calculate the potential, current and resistance at all the points in the feeder. Next by considering a location, we calculate the Full load voltage and the current and full load current. Note these values as the $0^{\text {th }}$ Iteration as $\mathrm{V}_{\mathrm{FL} 0}$ and $\mathrm{I}_{\mathrm{FL} 0}$ and then calculate the voltage regulation $\mathrm{VR}_{0}$. Now incorporate the Distributed generator Solar PV point of a particular capacity, at that point. Again calculate the Voltage regulation at that point, $\mathrm{VR}_{1}$. Compare this $\mathrm{VR}_{1}$ with $\mathrm{VR}_{0}$. This should be less than the VR0. If not, change the capacity of the DG and repeat the process till we achieve the desirable Voltage Regulation of $8 \%$. Now we use the above values in the PSO algorithm to get the pbest and gbest locations.

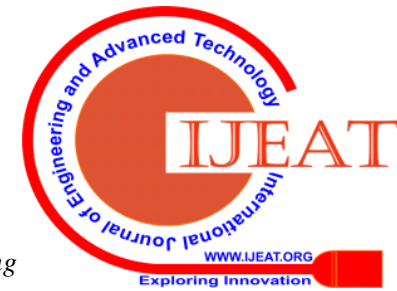


If the parameters are satisfied, stop the process else repeat the steps for calculating the Voltage regulation for the proposed system.

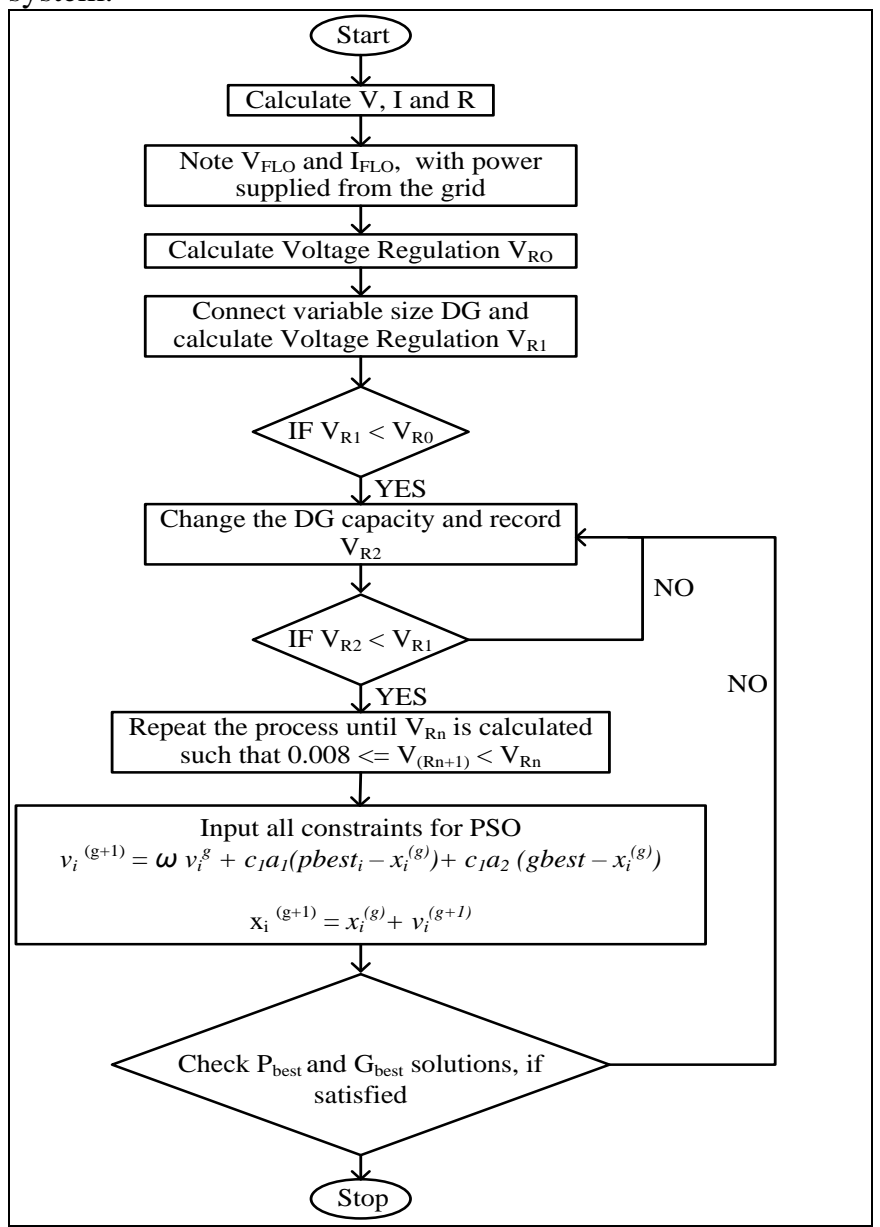

\section{OPTIMAL SIZING AND POSITIONING OF THE PROPOSED SYSTEM}

In Table 1, some selected Bus values with their respective voltage regulations are tabulated, which falls in the critical region.

On the analysis of the SLD of distribution network it is observed that the entire load is being feed from single Grid. It indicates poor contingency into the network. The Load flow study indicates that the Voltage regulation at $415 \mathrm{~V}$ side is around $8.5 \%$ on an average in all the buses except the Voltage regulation for Bus 6 (which is connected with $E$ bus through $100 \mathrm{kVA}$ transformer) is $11 \%$, which is exceeding the limit. To improve the voltage regulation of network, we propose a renewable source of energy as distributed generator.

Figure 8: Flowchart of proposed methodology

Table 1: Voltage regulation

\begin{tabular}{|c|c|c|c|c|c|c|c|}
\hline Bus & $\begin{array}{c}\text { No Load } \\
\text { Terminal } \\
\text { Voltage } \\
(\mathbf{k V )}\end{array}$ & $\begin{array}{c}\text { Full Load } \\
\text { Terminal } \\
\text { Voltage } \\
(\mathbf{k V})\end{array}$ & $\begin{array}{c}\text { Percentage } \\
\text { Voltage } \\
\text { Regulation }\end{array}$ & Bus & $\begin{array}{c}\text { No Load } \\
\text { Terminal } \\
\text { Voltage (kV) }\end{array}$ & $\begin{array}{c}\text { Full Load } \\
\text { Terminal } \\
\text { Voltage } \\
\text { (kV) }\end{array}$ & $\begin{array}{c}\text { Percentage } \\
\text { Voltage } \\
\text { Regulation }\end{array}$ \\
\hline Bus1 & 0.415 & 0.384 & 8.1 & Bus62 & 0.415 & 0.384 & 8.1 \\
\hline Bus2 & 0.415 & 0.384 & 8.1 & Bus63 & 0.415 & 0.382 & 8.6 \\
\hline Bus5 & 0.415 & 0.384 & 8.1 & Bus76 & 0.415 & 0.384 & 8.1 \\
\hline Bus6 & 0.415 & 0.374 & 11.0 & Bus77 & 0.415 & 0.384 & 8.1 \\
\hline Bus12 & 0.415 & 0.381 & 8.9 & Bus78 & 0.415 & 0.384 & 8.1 \\
\hline Bus13 & 0.415 & 0.384 & 8.1 & Bus79 & 0.415 & 0.384 & 8.1 \\
\hline Bus14 & 0.415 & 0.383 & 8.4 & Bus80 & 0.415 & 0.384 & 8.1 \\
\hline Bus22 & 0.415 & 0.383 & 8.4 & Bus81 & 0.415 & 0.382 & 8.6 \\
\hline Bus23 & 0.415 & 0.384 & 8.1 & Bus82 & 0.415 & 0.384 & 8.1 \\
\hline Bus24 & 0.415 & 0.382 & 8.6 & Bus83 & 0.415 & 0.384 & 8.1 \\
\hline Bus25 & 0.415 & 0.384 & 8.1 & Bus88 & 0.415 & 0.382 & 8.6 \\
\hline Bus37 & 0.415 & 0.383 & 8.4 & Bus89 & 0.415 & 0.384 & 8.1 \\
\hline Bus48 & 0.415 & 0.384 & 8.1 & Bus90 & 0.415 & 0.384 & 8.1 \\
\hline Bus49 & 0.415 & 0.383 & 8.4 & Bus91 & 0.415 & 0.382 & 8.6 \\
\hline Bus53 & 0.415 & 0.382 & 8.6 & Bus92 & 0.415 & 0.384 & 8.1 \\
\hline Bus55 & 0.415 & 0.383 & 8.4 & Bus93 & 0.415 & 0.384 & 8.1 \\
\hline Bus56 & 0.415 & 0.382 & 8.6 & Bus94 & 0.415 & 0.382 & 8.6 \\
\hline Bus61 & 0.415 & 0.384 & 8.1 & Bus119 & 0.415 & 0.382 & 8.6 \\
\hline
\end{tabular}

In the proposed system, Power to be received at the load by Solar PV array system is the multiplier of the load required and the potential of the LT side. The total solar power radiation per day is calculated by the average window period of the solar insolation. Voltage regulation is calculated and the Energy balance equation is verified in the MATLAB using PSO for the optimization of the System sizing. Then, the units of power are calculated by the generation of the energy by the panels of the specific capacity and henceforth the system installation and tariff per year are calculated thereby helping in deciding the Payback and designing the Optimum system for the improved voltage profile at the optimum cost. 
Optimal Position for the setting up of Solar Plant is at $415 \mathrm{~V}$ side on $\mathrm{T} 6$ bus with a size of $47 \mathrm{~kW}$. With the integration of DG at bus T6, the Voltage Regulation improves from $11 \%$ to $8.0 \%$. The line losses at bus T6 are reduced to $5.90 \mathrm{~kW}$ in place of $11.31 \mathrm{~kW}$ after the incorporation of DG i.e. a saving of $47.81 \%$ in the line losses.

After the Sizing and Positioning of the Solar DG at T6, Load Flow Analysis yielded a resultant system loss of $143.21 \mathrm{~kW}$ which was less than the value of the Load Flow Analysis of the system with $151.74 \mathrm{~kW}$ system losses. Henceforth, the overall system losses are reduced by $5.62 \%$ after incorporation of Solar Distributed Generator.

The Figure 9 depicts the ETAP model of the feeder under analysis, in which the Solar DG is placed. Also Figure 10 shows the ETAP model of T6 bus where the Solar DG is integrated for the Voltage regulation improvement and reduction in the system losses

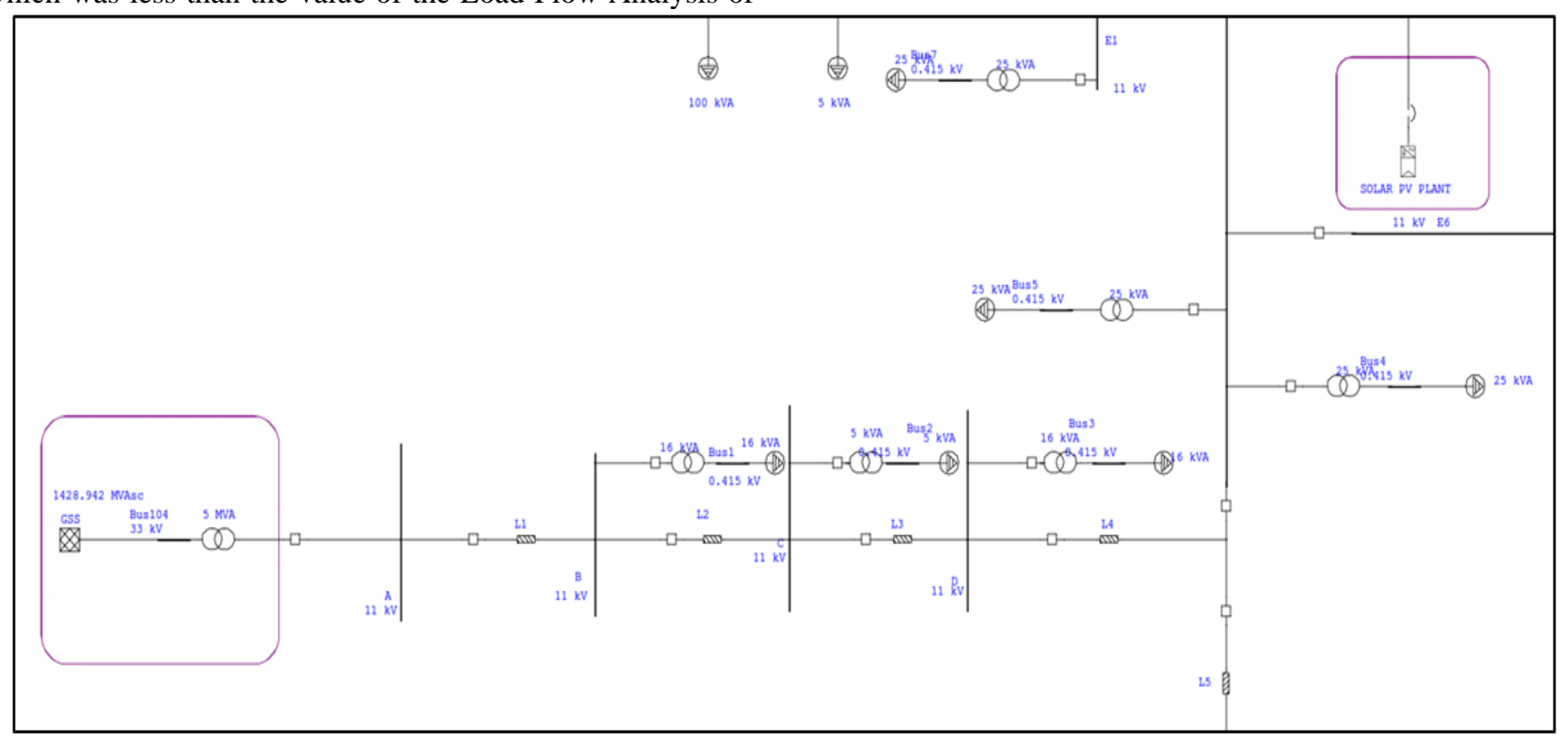

Figure 9: ETAP model of feeder under analysis

Figure 10: ETAP model of Bus T6

The cost of system is also optimized with an overall cost of INR 21, 15, 000 and payback period is 6.4 years. Hence, the Optimum Size and the Location of the Grid Integrated Distributed Generator is obtained for the improved voltage profile and better economics of the system.

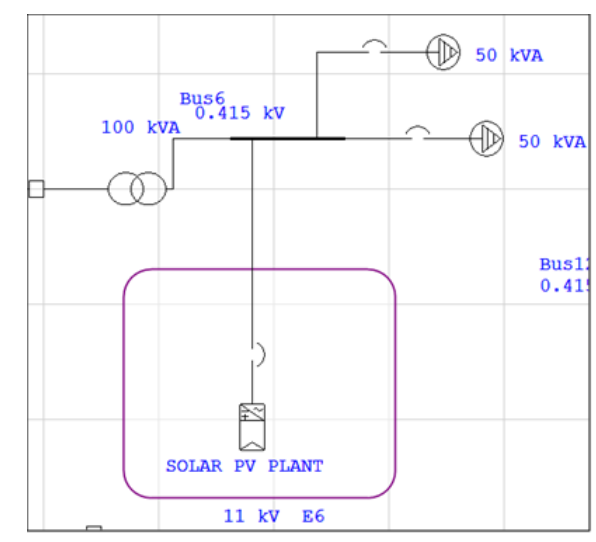




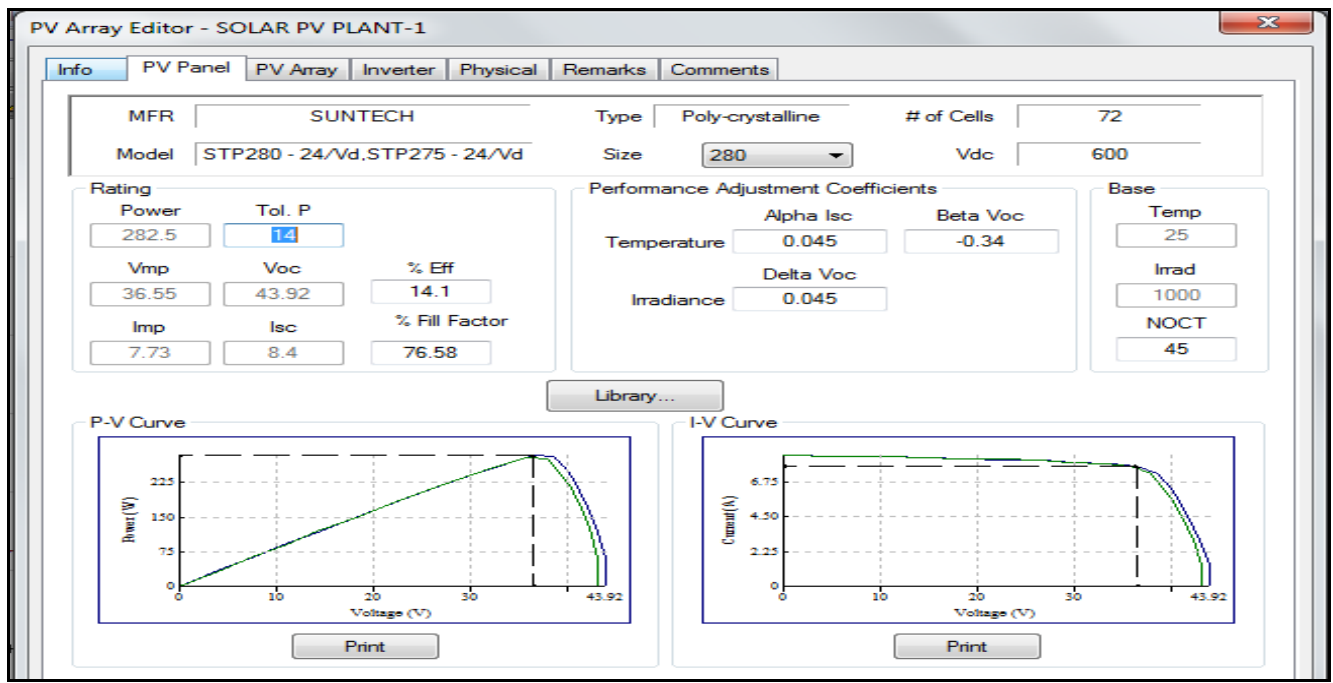

Figure 11 shows the results of the parameters for the PV modelling in the ETAP software for the Optimal sizing of the DGES.

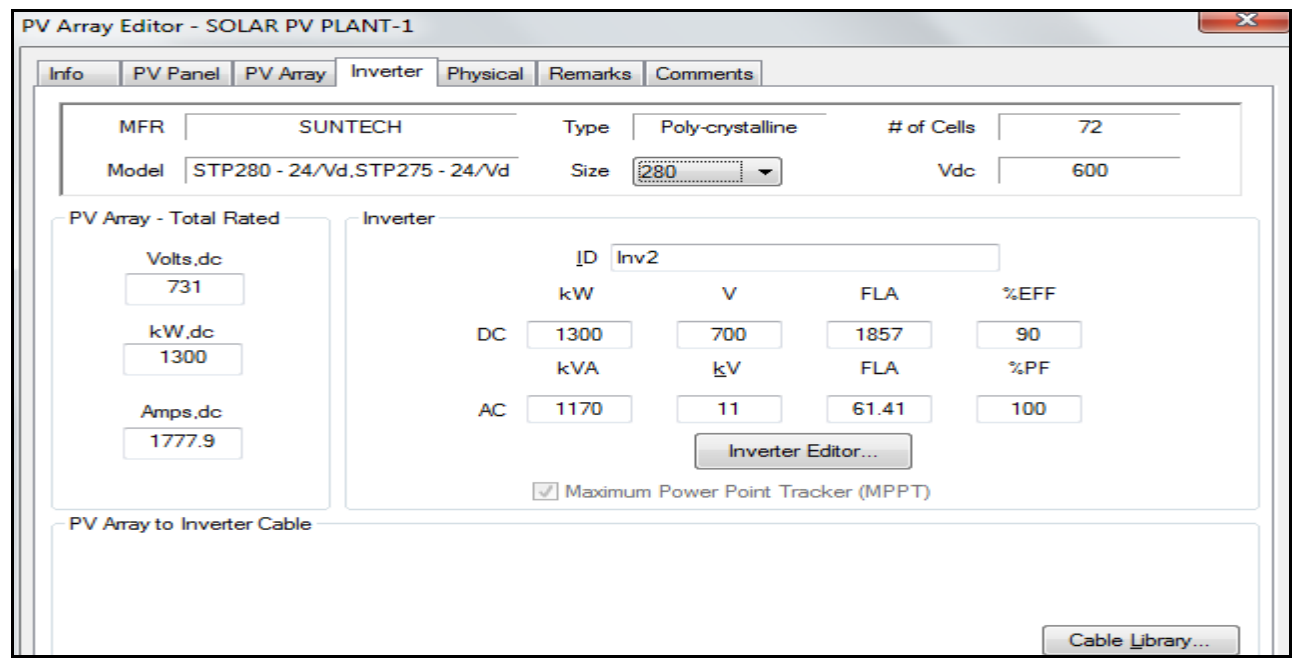

Figure 11(a): PV Array Editor for PV Panel and Figure 11(b): PV Array Editor for Inverter

The above figures also show the PV and IV Curve when the desired parameter obtained from the PSO Algorithm values are fed into the ETAP software for the modelling of the PV is done for the minimization of the Voltage Regulation.

\section{RESULTS}

A live working feeder is considered and all the existing feeder data of Deetyakhedi feeder, Piplod Grid Sub-Station in the Jhalawar Circle, Rajasthan State is taken for the research work. Load flow analysis is done on a Power System Analysis Software named ETAP which yielded the value of total system losses to be $151.74 \mathrm{~kW}$. Then Voltage Regulation (VR) is done on the HT and LT Side of the feeder as value of HT being very high, voltage regulation at HT side is $3.8 \%$, so no changes are required to be done here.

On LT side, Various VR's are obtained in the range of 8.1-8.9\% which is permissible for a Weasel Conductor but at Bus $6, \mathrm{VR}$ is $11 \%$ and this is the area of focus.

The Sizing and Positioning of Solar is done by PSO on MATLAB Software to bring this exceeding voltage regulation value into permissible limits. Size and Capacity of this Solar DG is compared by the Energy Balance Approach with PSO on MATLAB Software. [26]

Again the Load flow analysis of the new system with the Integrated Solar DG is done on ETAP for the verification of the System Improvement and the results yielded that the Voltage regulation improved to $8 \%$ from $11 \%$ and losses of $143.21 \mathrm{~kW}$ are observed.

Reduction in losses $=151.74$ (Before DG) -143.21 (After DG) $=8.53 \mathrm{~kW}$; implies $5.62 \%$ of system improvement after incorporation of Solar DG. Costing of the System and the Payback period is calculated, resulting in values of INR 21, 15,000 and is 6.4 years respectively.

Results: The below Table 2 shows all the results obtained from the Optimal Sizing algorithm using the Particle Swarm Optimization technique in MATLAB. 


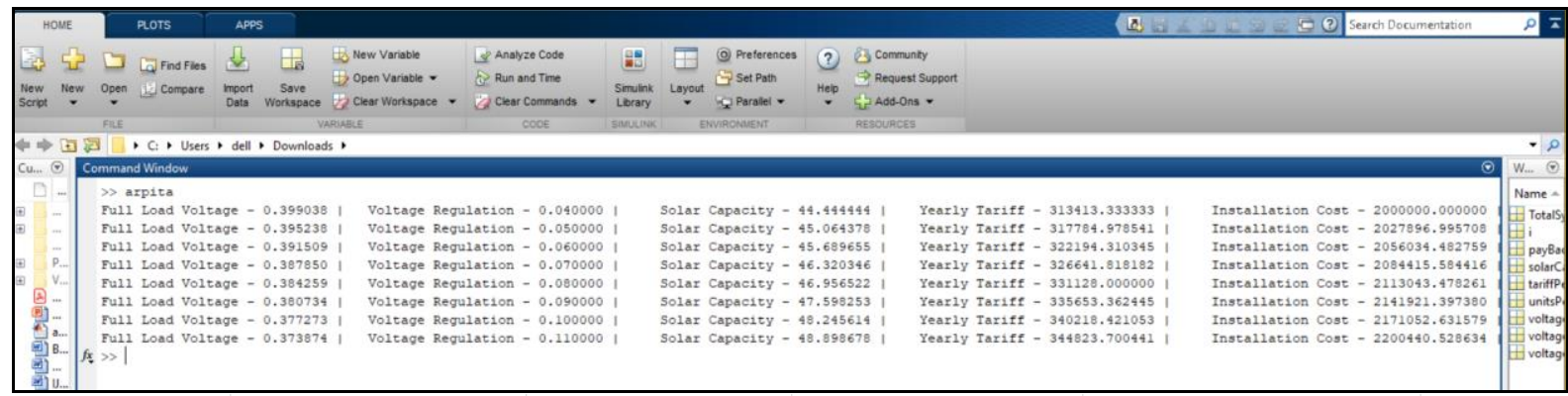

\begin{tabular}{|c|c|c|c|c|c|}
\hline \multicolumn{6}{|c|}{ Matlab Results } \\
\hline Full Load Voltage - 0.399038 & Voltage Regulation - 0.040000 & Solar Capacity - 44.444444 | & Yearly Tariff - 313413.333333 | & Installation Cost - 2000000.000000 | & PayBackPeriod - 6.381349 \\
\hline Full Load Voltage - 0.395238 & Voltage Regulation - 0.050000 & Solar Capacity - 45.064378 & Yearly Tariff - 317784.978541 | & Installation Cost - 2027896.995708 | & PayBackPeriod - 6.381349 \\
\hline Full Load Voltage - 0.391509 & Voltage Regulation - 0.060000 & Solar Capacity - 45.689655 | & Yearly Tariff - 322194.310345 | & Installation Cost - 2056034.482759 | & PayBackPeriod - 6.381349 \\
\hline Full Load Voltage - $0.387850 \mid$ & Voltage Regulation - 0.070000 & Solar Capacity - 46.320346 | & Yearly Tariff - 326641.818182 | & Installation Cost - 2084415.584416 | & PayBackPeriod - 6.381349 \\
\hline Full Load Voltage - 0.384259 & Voltage Regulation - 0.080000 & Solar Capacity - 46.956522 | & Yearly Tariff - 331128.000000 | & Installation Cost - 2113043.478261 | & PayBackPeriod - 6.381349 \\
\hline Full Load Voltage - 0.380734 & Voltage Regulation - 0.090000 & Solar Capacity - 47.598253 | & Yearly Tariff - 335653.362445 | & Installation Cost - 2141921.397380 | & PayBackPeriod - 6.381349 \\
\hline Full Load Voltage - 0.377273 & Voltage Regulation - 0.100000 & Solar Capacity - 48.245614 | & Yearly Tariff - 340218.421053 | & Installation Cost - 2171052.631579 | & PayBackPeriod - 6.381349 \\
\hline Full Load Voltage - 0.373874 & Voltage Regulation - 0.110000 & Solar Capacity - 48.898678 & Yearly Tariff - 344823.700441 | & Installation Cost - 2200440.528634 & PayBackPeriod - 6.381349 \\
\hline
\end{tabular}

Table 2: Optimal MATLAB results for PV Sizing and System Costing

\section{CONCLUSION} energy system (DGES) using PSO has been explained in this paper. The objective was to limit the framework cost, bringing the voltage regulation in the optimal range of permeability with the condition of satisfying the consumer load end and fulfilling a lot of streamlining limitations. Consumer load balance as one of matrix integrator applications has been acquainted with get a disseminated burden profile, lessen the whole grid framework cost and diminish $\mathrm{CO}_{2}$ emanation.

The PSO system has been executed in this paper to complete the streamlining procedure. The reproduction results verified that PSO is the promising enhancement procedures because of its capacity to arrive at the worldwide ideal with relative effortlessness and computational capability. The ideal framework segment size acquired by PSO fulfils all imperatives with least all out annualized cost. This philosophy can be effectively stretched out to resolve the load demand burden request at distribution end.

\section{REFERENCES}

1. Priyanka Paliwal, N. P. Patidar, R.K. Nema, "Planning of grid integrated distributed generators: A review of technology, objectives and techniques," in Renewable and Sustainable Energy Reviews, vol. 40, no., pp. 557-570, 2014.

2. Prabodh Bajpai, Vaishalee Dash; Hybrid renewable energy systems for power generation in stand-alone applications: A review; Renewable and Sustainable Energy Reviews 16 (2012) 2926-2939.

3. L.F Wang and C. Singh, "Compromise between Cost and Reliability in Optimum Design of An Autonomous Hybrid Power System Using Mixed-Integer PSO Algorithm," in Proc. IEEE Int. Conf. Clean Elect. Power (ICCEP 2018), Italy, pp.682-689, May 2018.

4. Arpita De, Arvind Mittal, "Stability and Optimization of Distributed generator: A Review," in International Journal of Electrical and Electronics Engineering Research, vol. 04, no. 04, pp. 1-10, Aug. 2017.

5. C.L.T.Borges, "An overview of reliability model sand methods for distribution systems with renewable energy distributed generator," in Renewable and Sustainable Energy Reviews, vol. 16, no. 06 , pp. 4008-4015, 2012.

6. A. Barin, L.F. Pozatti, L.N. Canha, R.Q. Machado, A.r. Abaide, "Multi-objective analysis of impacts of distributed generator placement on the operational characteristics of networks for distribution system planning" in International Journal Electric Power Energy System, vol. 32, no. 10 , pp. 1157-1164, 2017.

7. Aris Kornelakis, Yannis Marinakis; Contribution for optimal sizing of grid-connected PV-systems using PSO; Technical University of Crete,
An approach for ideal estimating of PV Distributed generator

Department of Production Engineering and Management, Greece; Renewable Energy 35 (2018) 1333-1341

8. Jiabing H, Heng N, Bin H, Yikang H, Zhu ZQ, "Direct active and reactive power regulation of DFIG using sliding-mode control approach," in IEEE Trans Energy Convers, vol. 25, no. 10, pp. 1028-39, 2010.

9. Satish Kansal, B.B.R. Sai, Barjeev Tyagi, Vishal Kumar, "Optimal placement of distributed generator in distribution networks," in International Journal of Engineering, Science and Technology, vol. 03, no. 03, pp. 47-55, 2011.

10. Pavlos S. Georgilakis, Nikos D. Hatziargyriou, "Optimal Distributed generator Placement in Power Distribution Networks: Models, Methods, and Future Research," in IEEE Transactions on Power Systems, vol. 28, no. 03, pp. 3420-3428, Aug. 2013.

11. Bindeshwar Singh, K.S. Verma, Deependra Singh, S.N. Singh, "A Novel Approach For Optimal Placement Of Distributed generator \& Facts Controllers In Power Systems: An Overview And Key Issues," in International Journal of Reviews in Computing, vol. 07, no. 09, pp. 29-54, Sep. 2018.

12. Robert Passey, Ted Spooner, Iain MacGill , Muriel Watt, Katerina Syngellakis, "The potential impacts of grid-connected distributed generator and how to address them: A review of technical and non-technical factors," in Energy Policy, vol. 39, no. 10, pp. 6280-6290, 2015.

13. Wen-Tsai Sung, Hung-Yuan Chung, "A distributed energy g network system based on data fusion via improved PSO," in SciVerse ScienceDirect, vol. 55, no. 12, pp. 368-374, Sep. 2014.

14. Wolf D. Grossmann, Iris Grossmann, Karl W. Steininger, "Distributed solar electricity generation across large geographic areas, Part I: A method to optimize site selection, generation and storage," in Renewable and Sustainable Energy Reviews, vol. 25, no. 10, pp. 831-843, 2013.

15. Subho Upadhyay, M.P. Sharma, "A review on configurations, control and sizing methodologies of hybrid energy systems," in Renewable and Sustainable Energy Reviews, vol. 38, no. 15, pp. 47-63, 2014.

16. Nadeeshani Jayasekara, Peter Wolfs, Mohammad A.S. Masoum, "An optimal management strategy for distributed storages indistribution networks with high penetrations of PV," in Electric Power Systems Research, vol. 116, no. 05, pp. 147-157, 2014.

17. Gareth P. Harrison, Antonio Piccolo, Pierluigi Siano, A. Robin Wallace; "Hybrid GA and OPF evaluation of network capacity for distributed generator connections"; Electric Power Systems Research, ScienceDirect; vol. 78; pp 392-398; 2015.

18. Mohamed A. Mohamed, Ali M. Eltamaly, Abdulrahman I. Alolah; PSO-Based Smart Grid Application for Sizing and Optimization of Hybrid Renewable Energy Systems; PLOS One; DOI:10.1371/journal.pone.0159702 August 11, 2016

19. S.P. Chowdhurya, S. Chowdhurya, P.A. Crossley; "Islanding protection of active distribution networks with renewable distributed generators: A comprehensive survey"; Electric Power Systems Research, ScienceDirect; vol.79; pp 984-992; 2014.

\section{Published By:}

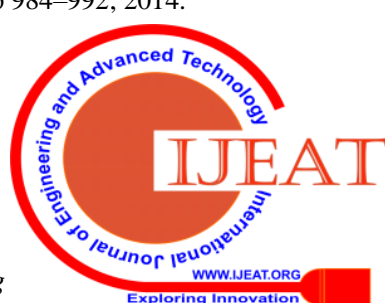


20. Mohammad S. Widyan, Rolf E. Hanitsch; "Operating point stability analysis of SMIB power system equipped with high PV penetration"; Electrical Power and Energy Systems, ScienceDirect; vol. 55; pp 522-530; 2014.

21. Rajkumar Viral, D.K.Khatod; "Optimal planning of distributed generator systems in distribution system: A review"; Renewable and Sustainable Energy Reviews, SciVerse Science Direct; Vol. 16; pp 5146-5165; 2015.

22. Srinivasa Rao Gampa, D. Das; "Optimum placement and sizing of DGs considering average hourly variations of load"; Electrical Power and Energy Systems, Science Direct; vol. 66 (2015) 25-40; 2016.

23. Nabila Nouaouria, Mounir Boukadoum, Robert Proulx; "Particle swarm classification: A survey and positioning- Pattern Recognition"; SciVerse Science Direct; vol 46; pp 2028-2044; 2015.

24. Ishita Biswas, Prabodh Bajpai; "Optimal sizing of PV-FC-Battery hybrid system with Energy Based Approach and PSO for the research project VDA-I under grant by Vodafone IIT centre of Excellence in Telecommunication"s" (VICET), IIT Kharagpur; 2016.

25. Jackson John Justo, Francis Mwasilu, Ju Lee, Jin-Woo Jung; "AC-microgrids versus DC-microgrids with distributed energy resources: A review"; Renewable and Sustainable Energy Reviews, SciVerse ScienceDirect; vol. 24; pp 387-405; 2015.

26. M. Kaviani, R. Riahy, S. Kouhsari.; "Optimal design of a reliable hydrogen-based stand-alone wind/PV generating system; considering component outages"; Renewable Energy; vol. 34(11); pp 2380-2390; 2016.

27. Mohammad Mahdi Rezaei , Jafar Soltani; “A robust control strategy for a grid-connected multi-bus microgrid under unbalanced load conditions"; Electrical Power and Energy Systems, ScienceDirect; vol. 71; pp 68-76; 2015.

28. Ruifeng Shi, Can Cui, Kai Su, Zaharn Zain; "Comparison Study of Two Meta-heuristic Algorithms with Their Applications to Distributed generator Planning"; Energy Procedia; vol 16; pp 245-252; 2018.

29. A. Askarzadeh, Dos Santos Coelho; "A novel framework for optimization of a grid independent hybrid renewable energy system: A case study of Iran"; Solar Energy; vol 12; pp 383-396; 2015.

30. Jean-François Toubeau, François Vallée, Zacharie De Grève, Jacques Lobry; "A new approach based on the experimental design method for the improvement of the operational efficiency in Medium Voltage distribution networks"; Electrical Power and Energy Systems, ScienceDirect; vol. 66; pp 116-124; 2015.

31. N.K. Roy, H.R. Pota, M.J. Hossain; "Reactive power management of distribution networks with wind generation for improving voltage stability"; Renewable Energy, SciVerse ScienceDirect; vol 34; pp 628-641; 2016.

32. P.Veena, V.Indragandhi, R.Jeyabharath, V. Subramaniyaswamy; "Review of grid integration schemes for renewable power generation system"; Renewable and Sustainable Energy Reviews ScienceDirect; vol 34; pp 628-641; 2018.

33. M.J. Hossain, T.K. Saha, N. Mithulananthan, H.R. Pota; "Robust control strategy for PV system integration in distribution systems"; Applied Energy; SciVerse ScienceDirect; vol. 99 pp 355-362; 2016.

34. W. B. Du, Gao, C. Liu, Z. Zheng, Wang; "Adequate is better: particle swarm optimization with limited-information"; Applied Mathematics and Computation; Vol 68; pp 832-838; 2017.

\section{AUTHOR'S PROFILE}

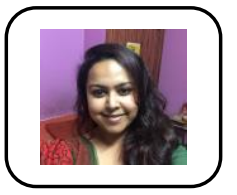

Arpita De, She is currently pursuing her $\mathrm{PhD}$ in Renewable Energy from MANIT, Bhopal. She holds a Master's Degree - M.Tech in Energy Systems Engineering and a Professional MBA degree in Power Management from University of Petroleum \& Energy Studies, Dehradun. She has done her Bachelor of Engineering (Hons.) in Electronics and Communication from Rajiv Gandhi Technical University. She also has a certification in Advanced Certificate in Power Distribution Management from Indira Gandhi National Open University and International General Certificate in Occupational Health and Safety from NEBOSH. 